\title{
Facilitating In-Service Teacher Training for Professional Development
}

Kenan Dikilitaş

Bahçeşehir University, Turkey

Ismail Hakki Erten

Hacettepe University, Turkey

A volume in the Advances in Higher Education and Professional Development (AHEPD) Book Series

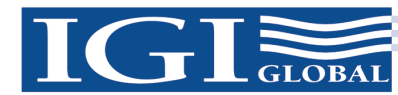


Published in the United States of America by

IGI Global

Information Science Reference (an imprint of IGI Global)

701 E. Chocolate Avenue

Hershey PA, USA 17033

Tel: $717-533-8845$

Fax: 717-533-8661

E-mail: cust@igi-global.com

Web site: http://www.igi-global.com

Copyright (C) 2017 by IGI Global. All rights reserved. No part of this publication may be reproduced, stored or distributed in any form or by any means, electronic or mechanical, including photocopying, without written permission from the publisher. Product or company names used in this set are for identification purposes only. Inclusion of the names of the products or companies does not indicate a claim of ownership by IGI Global of the trademark or registered trademark.

Library of Congress Cataloging-in-Publication Data

Names: Dikilitas, Kenan, 1973- editor.

Title: Facilitating in-service teacher training for professional development

/ Kenan Dikilitas and Ismail Hakki Erten, editors.

Description: Hershey PA : Information Science Reference, [2017] I Includes

bibliographical references and index.

Identifiers: LCCN 2016043919| ISBN 9781522517474 (hardcover) I ISBN

9781522517481 (ebook)

Subjects: LCSH: Teachers--In-service training. I Teachers--Professional

relationships. I School personnel management.

Classification: LCC LB1731 .F28 2017 I DDC 370.71/1--dc23 LC record available at https://lccn.loc.gov/2016043919

This book is published in the IGI Global book series Advances in Higher Education and Professional Development (AHEPD) (ISSN: 2327-6983; eISSN: 2327-6991)

British Cataloguing in Publication Data

A Cataloguing in Publication record for this book is available from the British Library.

All work contributed to this book is new, previously-unpublished material. The views expressed in this book are those of the authors, but not necessarily of the publisher.

For electronic access to this publication, please contact: eresources@igi-global.com. 


\title{
Chapter 12 Language Teachers' Beliefs and Practices: Lessons to Be Learnt for Facilitating Professional Development in Northern Cyprus
}

\author{
Leyla Silman-Karanfil \\ Middle East Technical University, Turkey \\ Mark Ian Payne \\ University of Sheffield, UK
}

\begin{abstract}
The impact of professional development programs on teachers' beliefs is still an exploratory field, with existing research finding both positive and weak impacts of teachereducation on teachers' beliefs. Building upon these findings, it is acknowledged that many challenges remain in designing focused professional development programs. This chapter addresses the problem by drawing on a study conducted with Higher Education teachers in North Cyprus. The study aimed to unveil teachers' beliefs about in-class codeswitching in teaching a foreign language. Using a qualitative methodology, data in the form of classroom observations, semi-structured interviews, course documents and field notes were collected and analyzed thematically. Findings suggest that cultures of learning, that is teachers' frameworks of expectations about successful teaching and learning, have a significant impact on teachers' beliefs. The authors suggest that an acknowledgement of cultural frames will facilitate appropriate professional development.
\end{abstract}




\section{INTRODUCTION}

'Cultures of learning' is still a relatively new concept in teacher education and existing assumptions about research on teacher education neglect the possible role cultures of learning play in shaping teachers' beliefs (e.g. Hobbs, Matsuo \& Payne, 2010). This chapter explores this issue in the context of the codeswitching (CS) practices of language teachers in a higher education institution in the north of Cyprus.

\section{MAIN FOCUS OF THE CHAPTER}

This chapter is divided accordingly: first definitions of the key concepts in this study, including, teachers' beliefs, cultures of learning and CS are offered. Then, the context and the methodology of this study with a description of the research framework, participants, and context are detailed. Next, the methods used in this study are set out and the data analysis is detailed. Later, the findings are presented and discussed critically. Finally, the conclusions drawn from the findings are presented. This part also includes the implications of the study and possible recommendations for teacher development programs.

\section{Teachers' Beliefs}

Teachers' beliefs have been defined from different perspectives. Taking Woods (1996) and Pajares' (1992) lead, this work suggests that beliefs are opinions of the appropriate pedagogical practices in class based on teachers' experiences or statements.

Though research analyzing the connection between teachers' beliefs and classroom practices is widespread (e.g. Breen, Hird, Milton, Oliver \& Thwaite, 2001), more research is required to gain an understanding towards the underlying factors responsible for the often match or mismatch between beliefs and practices.

One standpoint is to explore the factors influencing beliefs systems (e.g. Aldemir \& Sezer, 2009) which can be considered from two perspectives: external, e.g. language and institutional policies (Levis \& Farrell, 2007), and internal, e.g. personal language learning experiences (Ellis, 2006) or personal histories (i.e. culture, upbringing and experiences) (Aldemir \& Sezer, 2009).

The idea that prior learning experience and prior teachers' personal histories contribute to teachers shaping their belief systems would suggest that the construction of beliefs is personal (Woods, 2003). Taking this argument one step further, when considered from a cultural perspective, teachers with shared cultural backgrounds exert similar behaviors and have similar expectations of their students (see Hobbs \& Matsuo \& Payne, 2010) which may further imply that belief construction relates to a broader, overarching approach; the theory of cultures of learning.

\section{Cultures of Learning}

The notion of cultures of learning is used to describe teachers' frameworks of expectations, attitudes, values and beliefs about successful teaching and learning and how talk is used in interaction, among other aspects of learning (Jin \& Cortazzi, 2006). 
Studying teachers' cultures of learning is important in revealing information about their thought processes. There may be specific cultures of learning (e.g. Turkish) in terms of beliefs, expectations of communication and practices though some differences within a culture prevail (Littlewood, 2001). These may have an impact on teachers' use of the target language (TL), that is, it affects teachers' expectations in classrooms, how they understand the format of classroom instruction, the language to be used in the classroom and the way interaction should be achieved as part of the social creation of an educational discourse system (Jin \& Cortazzi, 2006). Thus, cultures of learning, among other elements (e.g. educational reforms) (Moore, Edwards, Halpin \& George, 2002), plays a considerable role in constructing social and educational identities.

Cultures of learning as a concept provides explanations for why teachers of shared background show similar patterns of practice in class such as evaluating their learners. In turn, the way in which learners interpret teachers' practices is likely to be shared by other learners from a similar culture; they do so to understand and judge professional behavior of both teachers of a similar culture and background and 'foreign' teachers' i.e. teachers who do not share their background. Moreover, those who go abroad to study or work frame their learning, initially, within their own cultures of learning (Jin \& Cortazzi, 2006).

Teachers' cultures of learning act as a filter through which teaching philosophies and methods are influenced. Pajares (1992) supports this idea: beliefs about education are formed by the time teachers start college, and these beliefs rarely change in adulthood. Accepting that cultures of learning guides one's behavior, and being aware of teachers' cultures of learning can provide a cultural framework for understanding their actions and talk (Jin \& Cortazzi, 2006).

\section{Code-Switching}

Despite much prior work on CS, it does not hold an exact definition among scholars, suggesting that the different realities around teachers' beliefs prevail within the field of CS too (Lin, 2013).

Toribio (2001) explains it as the ability, on the part of bilinguals, to alternate between their linguistic codes in the same conversation. Auer (1984) adds the multilingual touch arguing that CS is the alternating use of two or more languages by bilingual or multilingual speakers within a conversation, either in the same or in successive conversational turn(s). For Willans (2011), CS is the alternation between two separate codes (p.24). Taking Hobbs, Matsuo \& Payne's (2010) lead, in this study, CS refers to each time teachers and/or learners switch the code of communication. That is, in this case, when they switch from the language being taught (L2-English) to the mother-tongue (L1-Turkish) or vice-versa in the classroom.

Code-switching in language learning is not seen as an asset by all (Pan \& Pan, 2010), with some scholars rejecting it (e.g. Evans, 2009; Chambers, 1991) and others valuing it (e.g. Antón \& Dicamilla, 1999). For opponents, using L1:

- Is unnatural in that the exclusive use of L2 makes the classroom more like a monolingual learning atmosphere and an authentic place for learning,

- Undermines L2 learning. The presence of L1 prevents students from receiving the input they might be exposed to in real life (Chambers, 1991). 
These positions index support for Krashen's (1982) input hypothesis or Ellis' understanding of extensive input (Ellis, 2005, p. 217) whereby more L2 input brings about more success in L2 acquisition through comprehensible L2 input. Proponents opine that L1:

- Has a facilitating role in the L2 learning process, for example through boosting learners' selfconfidence (Seng \& Hashim, 2006; Auerbach, 1993).

- Cannot be isolated in terms of L2 learning and indeed is part of the process, as argued by Cummins and his 'Common Underlying Proficiency' (Cummins, 2000).

Research on language classroom CS includes describing teachers' attitudes towards CS, (e.g. Yavuz, 2012; Levine, 2003) the frequency of classroom CS (Polio \& Duff, 1994) and the difference between experienced and novice teachers based on the argument that novice teachers switch more than experienced ones (De La Campa \& Nassaji, 2009). Some studies, similar to the one that is the focus of this chapter, address the functions that cause teachers to switch codes, including:

- Managerial issues, including getting students' attention (Tabaku, 2014) and reprimanding students (Canagarajah, 1995);

- Making jokes to encourage a positive learning environment (Canagarajah, 1995); and

- And grammar explanations (Polio \& Duff, 1994) because of learners' L2 proficiency level or to save time (Tabaku, 2014).

\section{Linking Cultures of Learning with CS}

Hobbs, Matsuo \& Payne (2010) take a different perspective on CS as not just an act of being a novice, or experienced practitioner or influenced by contextual factors but dependent on prior cultures of learning. They conducted a qualitative study, observing the relationship between teachers' cultures and CS behavior in the UK among four secondary school teachers of Japanese, two native speakers (NS) and two non-native speakers (NNS) which revealed the differences in beliefs and experience about language learning (Hobbs, Matsuo \& Payne, 2010). These were also reflected in their views of both the teacher's role and learners' receptivity, thereby either reinforcing their commitment to L2 use or contributing to CS, i.e. switching to English (the contextual L1). This was verified with interviews where NS teachers expressed their positive attitude of L1 in language pedagogy while the NNS chose to reflect on how to increase L2 use (e.g. it depends on learners' proficiency level). They concluded that teachers coming from a positive culture of CS switch more than those exposed to more communicative methodologies. This mirrors the findings of Polat (2009), who suggests that teachers'and students' beliefs match, especially when they share the same linguistic and cultural background.

Thus, the cultural influences of the context in which CS takes place should be highlighted as, without this, 'descriptions of CS studies only present a partial picture of the underpinnings of these teachers' decisions' (Hobbs, Matsuo \& Payne, 2010, p. 46). 


\section{CONTEXT AND METHODOLOGY}

This section lays out the details of this research project, including the context for the study, the framework of the research, the participants, data collection and analysis. The key participants were TurkishCypriot teachers of English (henceforth TC/TCs) and 'native' Turkish teachers of English from Turkey (henceforth TR/TRs).

\section{Context}

The study took place at the School of Foreign Languages (SFL) of a private university in North Cyprus, the Turkish side of divided Cyprus (henceforth, the North Cyprus College (NCC)). The English-medium institution was selected purposively as it is the workplace of Silman-Karanfil who teaches English there. NCC is a trans-national campus, a branch of a state university in Turkey. SFL offers a preparatory program (Prep), which aims to provide the students whose level of English is below proficiency level with basic language skills so that they can pursue undergraduate studies. Prep courses are also referred to as English intensive programs (see Selvi, 2014). All of the courses in Prep are held five days a week. Prep is a one-year program and at the end of the year students take an exit exam, requiring $60 \%$ to pass. In terms of the Prep's language policy, a member of the academic board stated that Prep had a strictly L2policy, though there were no formal written guidelines. The courses offered at the time the study was conducted included: summer school classes (tutorial classes designed for those who could not pass the exit exam) and Pre-Intermediate (A2). The study was conducted with teachers teaching pre-intermediate, the immediate colleagues of Silman-Karanfil.

\section{Framework of the Research}

This study adopted an interpretive paradigm drawing on qualitative data using observations (Obs.), postobservation interviews (POINTs), semi-structured interviews (INTs), focus-group interviews (FGs) and follow-up interviews (FUs) as well as comprehensive field-notes and memos to allow the construction of analytical themes. The use of this paradigm also enabled the authors to gain an in-depth understanding of teachers' beliefs about CS and classroom culture.

The study was guided by four research questions as follows:

1. What are the CS beliefs of TC and TR teachers teaching TR students in North Cyprus?

This research question is related to how TCs and TRs perceived CS and their ideas towards codechoice (i.e. to CS or not) when teaching TR students in an EFL context.

2. What are the factors shaping TCs and TRs CS practices?

3. To what extent are TCs and TRs CS practices influenced by these factors?

These questions aimed to explore the features shaping teachers' awareness and ideas of CS. They also aimed to discover the impact of these features on characterizing TCs' and TRs' awareness and ideas of CS.

4. How do TCs and TRs utilize CS in-class and do practices differ?

This question aimed to explore TCs and TRs in-class code choices. It also sought to investigate if TCs' and TRs' in-class code choices differ with regards to their amount (i.e. in percentages) and use (i.e. functions). 


\section{Participants}

Ten university teachers of English (5 TCs and 5 TRs) participated in this study (see Table 1 Overview of participants) and were all selected using convenience sampling. They were sampled purposively in that they had to be actively teaching English and have at least a year of experience of the institution they were working at (Wellington, 2000, pp. 61-62). The profiles of the ten teachers (3 females and 7 males of both TR and TC heritages) are as follows:

In terms of the participants' backgrounds, of the five TCs, four (TC1, TC2, TC3, and TC4) were educated at English medium high-schools where they were exposed to language and content-based education. Three TCs (TC1, TC3, and TC4) had themselves had teachers who followed a strict English-only policy, with few uses of the L1. TC5 was educated at a state school where the medium of instruction was Turkish. She did not undergo a content-based English education, did not have NS teachers of English and had less English instruction per-week. More importantly, her English teachers used more L1 than L2 in their classes.

Of the TRs, TR4 graduated from an English-medium high school offering content-based education. Her teachers were both NS and NNS of English. She said that the NNS used Turkish to build rapport or discuss current issues in class. The other TRs' learning experiences (starting from high school) were mainly twofold. The first part involved a one-year intensive English 'prep' program in their state high-

Table 1. Overview of participants

\begin{tabular}{|c|c|c|c|c|c|}
\hline $\begin{array}{l}\text { Participant } \\
\text { No. }\end{array}$ & Pseudonyms & High School & BA Degree & Other Qualification(s) & $\begin{array}{l}\text { Teaching } \\
\text { Experience } \\
\text { in Years/At } \\
\text { Institution }\end{array}$ \\
\hline 1 & $\mathrm{TC} 1$ & *TMK, Nicosia & ELT, Turkey & $\begin{array}{l}\text { COTE}^{1} \mathrm{DOTE}^{2} \text { (not completed) } \\
\text { MA-in ELT in progress }\end{array}$ & $22 / 4$ \\
\hline 2 & $\mathrm{TC} 2$ & *BTMK, Nicosia & $\begin{array}{l}\text { ELL } \\
\text { Cyprus }\end{array}$ & $\begin{array}{l}\text { MA- in EHL }{ }^{3} \text {, Cyprus } \\
\text { TESOL }^{4} \text {-England }\end{array}$ & $12 / 1$ \\
\hline 3 & $\mathrm{TC} 3$ & *TMK, Famagusta & $\mathrm{ACL}^{5}$, Turkey & $\begin{array}{l}\text { MA-, MED }{ }^{6} \text { London } \\
\text { CELTA }^{7} \text { ICELT }^{8}\end{array}$ & $16 / 5$ \\
\hline 4 & $\mathrm{TC} 4$ & *TMK, Famagusta & ELT $^{9}$, Cyprus & ICELT & $10 / 1$ \\
\hline 5 & TC5 & $\begin{array}{l}\text { Lycee (went to } \\
\text { nursery in the UK) }\end{array}$ & ELT, Cyprus & $\begin{array}{l}\text { Attended workshops, seminars } \\
\text { and holds certificates. Worked } \\
\text { one to one with various teacher } \\
\text { trainers }\end{array}$ & $6 / 1$ \\
\hline 6 & TR1 & Super Lise & $\begin{array}{l}\text { ACL, } \\
\text { Turkey }\end{array}$ & $\begin{array}{l}\text { MA-in ELT } \\
\text { ICELT }\end{array}$ & $9 / 8$ \\
\hline 7 & TR2 & Super Lise & ACL, Turkey & $\begin{array}{l}\text { MA-in ELT } \\
\text { ICELT }\end{array}$ & $9 / 8$ \\
\hline 8 & TR3 & $\begin{array}{l}\text { Anatolian } \\
\text { High school }\end{array}$ & ELT, Turkey & $\begin{array}{l}\text { MA-in EFL in progress } \\
\text { ICELT }\end{array}$ & $4 / 4$ \\
\hline 9 & TR4 & $\begin{array}{l}* \text { TED Ankara } \\
\text { College }\end{array}$ & $\begin{array}{l}\text { ELL }^{10} \text {, } \\
\text { Turkey }\end{array}$ & $\begin{array}{l}\text { MA-in EFL in progress } \\
\text { ICELT }\end{array}$ & $2 / 2$ \\
\hline 10 & TR5 & $\begin{array}{l}\text { Anatolian teacher } \\
\text { training high school }\end{array}$ & $\begin{array}{l}\text { ELT, } \\
\text { Turkey }\end{array}$ & ICELT & $4 / 1$ \\
\hline
\end{tabular}

*English-Medium 
schools with approximately 20 hours of English classes a week. Participants' teachers utilized different language policies throughout the prep year; TR3's and TR5's teachers followed a mostly-L2 policy, while TR1's and TR2's teachers did not. The second part was focused on exam practice; English was used minimally and grammar lessons were conducted in a Grammar Translation Method format: L1 overtook L2. There was explicit grammar teaching with formulaic language written on the board and, for reading, strategies (TR3-INT1) were given to students to solve the questions without actually reading the whole text (TR2-INT2). There were no listening classes (TR1-INT1) and vocabulary learning was de-contextualized. There were vocabulary lists, from which the TR equivalents of words would be memorized.

\section{Methods}

The main data collection methods were observations (Obs.), post-observation interviews (POINTs), semi-structured interviews (INTs), focus group interviews (FGs) and follow-up interviews (FUs), In addition, comprehensive open field notes were written which allowed instances that would otherwise have been omitted to be captured (Yuan, 2001), such as gestures (e.g. 'Teacher smiles') and bodily actions (e.g. 'Teacher walks towards the student'). Furthermore, various documents were collected, including the English syllabus, teaching program, a selection of teachers' worksheets and course books.

The classes of the ten participants teachers were observed and audio-recorded, a series of $3 \times 50$-minute lessons for each of the teachers. During the observations, the researcher (Silman-Karanfil) acted as a non-participant observer. Observations were conducted in an unstructured manner in that there were no formal observation sheets. A two-stage transcription process (Wellington, 2000) was followed in that recordings were listened to and notes were added (e.g. times of actual CS) to the observation sheets.

Post-observation interviews were held as early as possible after the lessons in the form of adapted 'stimulated recall' drawing on the transcripts and key episodes rather than the audio recoded lessons (Borg, 2006, p.209). This allowed participants to elaborate on their thought processes and trigger discussions.

Taking Woods' (1996) lead, the semi-structured interviews were conducted with individual teachers and included questions related to the participants' past experiences and current lifestyles. Direct questions such as 'what do you think about....?' and reflective questions, such as 'could you reflect on...', were also included. After all the individual interviews and observations were completed, teachers took part in the one-hour focus groups (Wellington, 2000). Participants were asked general questions (e.g. 'why did you become a language teacher?') so that their beliefs and ways of teaching could be compared as a whole. Later, more specific questions were asked, (e.g. 'what makes us as teachers consider using English with our students as natural or not?')

There were three sets of follow-up interviews, the first conducted for clarifications, the second were conducted with TC3, TC4, TR1 and TR2 for clarification of some issues in the focus group and the third set was held 11 months later with all participants to see to what extent the study's conclusions were supported.

\section{Data Analysis}

A constructivist grounded approach (Charmaz, 2006) was applied in that the collected data were analyzed using memoing and constant comparison. All key episodes in the Obs, POINTs, FGs and FUs were noted in a Word document and later summarized in bullet points so that questions could be generated. These 
were later written up as memos then converted into a free-writing format and compared for analysis. As for the in-class CS, observations operated at the functional level, and a note was taken each time the participants switched from one function (i.e. explaining) to another (i.e. class management). There were no pre-determined functions and all were constructed after careful examination of each teacher's Obs. and the POINTs.

A thematic approach was used in the study (Braun \& Clarke, 2006), and in the following section the themes that were constructed will be discussed.

\section{FINDINGS AND DISCUSSION}

The key themes that were constructed (emerged) from the study were: Practices influenced by cultures of learning; Family background; Participants' former teachers; Prior learning experience; Framing teachers' leniency towards L1; Framing teachers' expectations of their students; Framing teachers' perceptions of class events. Each of these is discussed in turn, below. In discussing the themes, quotations are included, translated by Silman-Karanfil. All participants preferred to be interviewed in Turkish apart from TC1 and TR4 with TC4 transitioning from English to Turkish during the process. Bracketing is used in the quotes to refer to CS: for interviews from L1 to L2 (vice-versa for TC1 and TR4) and for observations the words in brackets refer to switches from L2 to L1.

\section{Practices Influenced by Cultures of Learning}

Teachers' previous teaching and learning experience, as well as their socio-cultural backgrounds (i.e. family, friends and peers), led them to believe in different things and their practices reflected these. To illustrate, when discussing how she had learnt English, TR3 stressed the importance of Turkish in her learning experience. She explained that she had had a lot of fun learning English back at a private institution (TR3-INT2) where she said there was more communicative work (i.e. games) and used L2, but later on stated that this kind of education would not have enabled her to pass exams, or even to become a teacher at NCC.

TR3's existing belief that L1 was useful in passing exams shaped her perception towards the use of L1 at NCC. She posited that she came to know that the system at NCC (which is also a part of her cultures of learning) was exam-based. Therefore, she saw a similarity between her own learning environment and her teaching environment and thus considered L1 to be useful. She added that this parallelism enabled her to empathize with her students. Thus, she used L1 based on past experiences, behaving in a way that she believed would work.

As for the TCs, however, they used L2 more than L1, as they did not receive as intense a test-based education as their TR counterparts. Thus, they did not put significant emphasis on teaching to pass exams. On the contrary, they even opposed this kind of teaching approach, again showing how they perceived the necessity of using L2. However, particularly TC5's greater experience with an environment where CS was natural both in and outside the class saw her use L1 more than her TC counterparts.

Therefore, if parallel cultures of learning between teachers and students foster empathy, then personal experience of NNS in learning becomes invaluable (Ellis, 2006). 


\section{Family Background}

The regular use of the TL by the TCs led to them experiencing 'bilingual language use' (i.e. having access to bilingualism regarding identity and family: Ellis, 2006, p.3), whereas the TRs were NNS with limited access to the TL. Family background affected participants perceiving L2 as natural or not and/ or whether there was room for L1 in their teaching.

From the TCs, two (TC1 and TC4) experienced enculturation. They said they saw themselves as NS because of their 'English' lifestyles (communicating in English out of school, reading English-books, watching English TV channels). These two participants were the ones who had stronger beliefs in language exposure and saw using L1 in the classroom as an act of misconduct:

I don't like it when I use LI to teach vocabulary. It's something I'm totally against (TC1-INT1).

However, with TC3 and TC5 there was not a total enculturation but more of a mixture of both cultures. For them, alternating between English and Turkish was something natural as it was how they used it in their personal lives. In explaining why their L1 use was higher compared to that of TC4, for example, TC5 said:

When I go to my mum's, my aunt and cousins come round too, and we speak in English because they all grew up in the UK ... when this lot are together, there is almost no Turkish. But my mood changes. A day comes when I also speak English, there are times they speak to me in Turkish, and I respond in English. And sometimes a day comes I insist on not using English (TC5-INT3).

Moving on to TC2, he was in-between enculturation, and a mixed culture. He implied that English and Turkish were part of his life but would not alternate between codes in his personal life.

Nonetheless, all TCs expressed that learning English for them was more like acquisition (e.g. TC2FU). Owing to their relatives in the UK and their close contact with them, enabled TCs to go through an informal education in their learning of English; thus experiencing the benefit of exposure.

As for the TRs, 'Turkishness' was at the center of their beliefs, affecting the way they perceived themselves and their language use:

And I really want to encourage them to integrate English into their own lives. That's not to say they should abandon their own culture. No way. Of course their mother culture, their mother language, I think it is their priority and for me as well (...) I really want them to learn about the culture of the language as well. And compare it with our own culture for example, so LI in every sense holds a very big part of my teaching practice. Because I really believe a person should be competent in their own language first. I mean language, literature, culture whatever it includes and they can learn about the second one as well (TR4-INT3).

The connection of this to L1 belief is that considering themselves native-like, or belonging to a mixed culture or solely Turkish, influenced teachers' leniency towards L1 use. For example, the TRs kept saying that it was unnatural for them to communicate in L2 with their TR students. Hence, as aforementioned, there was a feeling of 'devaluation' among those who did not consider themselves native with an L2only policy. 
Relating this to the school environment, the school's policy did not affect their beliefs, showing the mediating role of background over school policies. To illustrate, TC5 confessed she was not aware of the exact policy on the use of L1. Therefore, the school's policy was relatively less important as she behaved according to her feelings. She used the code she wanted to rather than the code she had to.

\section{Participants' Former Teachers}

Former teachers acting as role models also influenced participant teachers' beliefs. Most of them referred to the teachers they admired (TR3-INT1) and, in some cases, who had influenced their career choice (TR4-FG). Supporting studies by Numrich (1996) and Johnson (1994), former teachers were seen as positive contributors in shaping these participants' L1 beliefs (TC1-INT1; TR4-INT1). Their former teachers' use of L1 provided de facto guidelines for when to use L1. These included building rapport, getting attention, reprimanding (usually with mitigating effect) and at times explaining difficult points. To illustrate, TC1 explained:

TC1: ... if the class was getting really naughty and making jokes about the relationship about Romeo and Juliet you know awkward jokes, she would probably say (C'mon kids!) [with a Cypriot accent; like a mother would say to her kids] just to make us stop. Things like that. Definitely not anything to do with the lesson (TC1-INT2).

Referring to her own language practices, TC1 only used L1 for explaining, such as when she was doing a reading lesson and felt that students did not understand. Much of her L1 use had a mitigating effect where students would laugh. For example, in Obs. 2 students were repeatedly making the same mistake by reading the line they were not supposed to. After many turns she said:

(The lights are on but nobody's home. I'm not saying anything else) (TC1-Obs. 2).

Likewise, TR4's practice also resonated with her own teachers', whom she said had influenced her (i.e. as a role-model) in her decision to become a teacher herself:

She [teacher] would use mostly English. But she would tell jokes in Turkish. They were really hilarious because they were to the point, always. Or when everyone started speaking, she would definitely switch to Turkish and we would all wake up. I remember that's why I think switching works in my class (TR4-FU).

She gave more specific details about her teacher's code-choice:

She would always use English but when she wanted to get our attention she would switch to Turkish ... she would also talk to us about the current issues or our problems. It would be in Turkish, definitely. She also spoke to us in Turkish. And I remember she used words like (honey, sweetie), so it really affected me I think (TR4-INT2).

TR4's parallelism with her former teacher's practice lay in her choice to alternate in similar situations. To illustrate, in one of her classes she chatted in L1 about a current issue: the need to clean the trash. In other classes she used L1 in teaching difficult points (i.e. grammar and vocabulary) and discussed 
a film they had watched and talked about the upcoming holidays. In all observations, she also used L1 to get attention ('C'mon!') to bring them back to the lesson. L1 was a tool for her to build rapport with students and a chance to express themselves (TR4-INT3), which she witnessed had worked before as a student herself.

\section{Prior Learning Experience}

Participants' prior learning experiences had a facilitating role in participants' CS beliefs in that they reverted to their prior learning experiences (as students) in their beliefs about code choice (Hobbs, Matsuo $\&$ Payne, 2010). They recalled both the negative and the positive incidents as pupils. Certain teachers wanted to bring into class their learning habits.

For the TCs (apart from TC5), English language exposure at school was perceived as a positive experience. To illustrate, TC1 opined:

You instantly start thinking that if I had learnt well that way, so could the students (TC1-FU).

Moreover, both TC1 and TC4 expected to be addressed as 'Miss' and 'Sir' respectively in that it was a habit from school [as a student] (TC4-POINT3). Both teachers' classroom instances support this belief as exemplified by an example from TC1's class:

Student: (my hodja)

TC1 (I just couldn't teach you to say) Miss (TC1-Obs.2).

Similarly, when TC4 was addressed as 'Sir' by a student, he was asked how it made him feel. He said it made him feel good in that for him it was a proper way to address teachers according to the English culture. He also said that was the way he addressed his own teachers. He also pointed out that students addressing their teachers otherwise was 'negative interference' (Krashen, 1982, p.27):

... sometimes they call me 'teacher!' and I answer them by saying [yes student] and they get surprised. That's why I find (Sir) more appropriate or TC4 [his name], or Mr. TC4 [his surname]. Mr. TC4 is too formal, I think (TC4-POINT3).

His belief in L2 exposure being so strong, TC4 provided his students in return with language exposure. The authors believe the reason for students' insistence on not being called 'teacher' could be a difference between L1 and L2 rules and students' culture. TC4 was also consistent in his expectations and his own practice. He addressed his students as 'ladies' and 'gents' (TC4-Obs.1).

Unlike the four TCs, the TRs plus TC5, however, stated that it was 'unnatural' and 'weird' for them to address their students using English, thus, they used this function in L1, again related to the TRs' former learning experience:

..when I say (friends) I don't feel good (...) actually I did it once and not intentionally but it just came out like that. And the student said to me: my hodja what's with the (friend)? I thought he was right, what's with the (friend)? (TR3-INT3) 
However, TRs' negative experience in not receiving exposure shaped their beliefs. To illustrate, TR3 who described the effects of the absence of exposure on her education opined:

Because my education was based on exams ... Turkish was the dominant language not English. And, actually, later on, when I became a student at university, I felt its [English] absence, I felt that I couldn't speak fluently (...) that's why, maybe, I think I can say that students should hear, be exposed, as much as possible to English ... (TR3-INT3).

For TC5 and the TRs, prior learning experience also played an integral role in their leniency towards L1 use. Their experience in this respect made them empathize with students' desire for L1 (Ellis, 2006). They pointed to the tensions: crowded classes, students with low proficiency; whereby providing exposure (Payne, 2011) was challenging and switches to L1 inescapable (Kraemer, 2006):

.......who'd understand them [the English teachers] 35-40 people in one class? With two or three English classes in a week (...) what sort of a background did they [the students] come from? Well, only if they came from London like us or had a family or relatives there they could be familiar [with the language] (...) Even for us, although we're teaching it ... you know how hard it is to speak English all the time (TC5-INT3).

One of the biggest tensions was the pressure brought by exams. Coming from a background where there were high-stake exams, TC5 and the TRs attached importance to exam practice. Making sure students understood (e.g. TR3-INT2) and covering more exam practice (e.g. TR1-INT1) became more prominent and required L1, perhaps because they saw their own experience parallel to that of the students. Thus, when exam practice was involved they switched to L1. For example, TR2 said:

When we study for the exam, I answer students' Turkish questions in Turkish. I try to be (resistant) when studying Language Leader [the course book] (TR2-FG).

TR3 also said that L2 may be too risky in the exam-based environment and that she did not want to be responsible for student failure, and thus used L1.

Consequently, prior learning experiences set de facto guidelines for teachers and frame their practices (Borg, 2003). However, the influences on their practices were not merely their prior teachers, but also the way cultures of learning affected their frame towards teaching. If this is only considered from Borg's (2003) perspective, then it would suggest that teacher A, who grew up in a similar culture to teacher B, would use more L2 if she had had teachers who used L2-only. Based on this study's findings and interpretation of them, the authors would claim that one's learning or teaching experience within his/ her culture is equally significant. Here is an example from TR4, a supporter and user of L1, who had both NS and NNS teachers: 
It was a foreigner [the NS] talking about something for a short amount of time. At first I found it difficult but I don't remember feeling stressed, crying or something like that (...) she [the NNS] wouldn't speak Turkish much but maybe knowing that she would respond to you, and she would understand you, was more relaxing back then .... But I still feel the Turkish lady was like a buffer zone, a supporting point I could turn to whenever I needed, but then again she wouldn't speak Turkish much but knowing that she would if I needed, that was kind of a more positive thing for me (TR4-FU).

In informal talks, she said she had considered her NS teacher only as a benefit in improving her speaking skills, but her NNS in developing her accuracy, and knowledge of grammar (a knowledge which is required at NCC because student exam papers are penalized for lack of accuracy).

TR4's example above indicates that the culture in which she was brought up affected the way she had perceived her NS teacher and her current beliefs.

\section{Framing Teachers' Leniency Towards L1}

Findings of this study evidenced that teachers' leniency in L1 use was dependent on teachers' perceived closeness to the language, which was due to internal factors including family background, previous teachers and prior learning experience.

For the TCs, there was a relation between 'Turkishness' and L1 leniency. The closer the participants considered themselves to the target culture (i.e. English), the less lenient they became towards the use of L1. TC5 said that she could use L1 up to 50\% of the time, TC3 30\%, TC2 not much and TC1 and TC4 implied that it should not be used at all. The following figure depicts the correlation between TCs' L1 leniency and their closeness to the target culture:

Figure 1. TCs' leniency towards L1-stated beliefs

L1 leniency

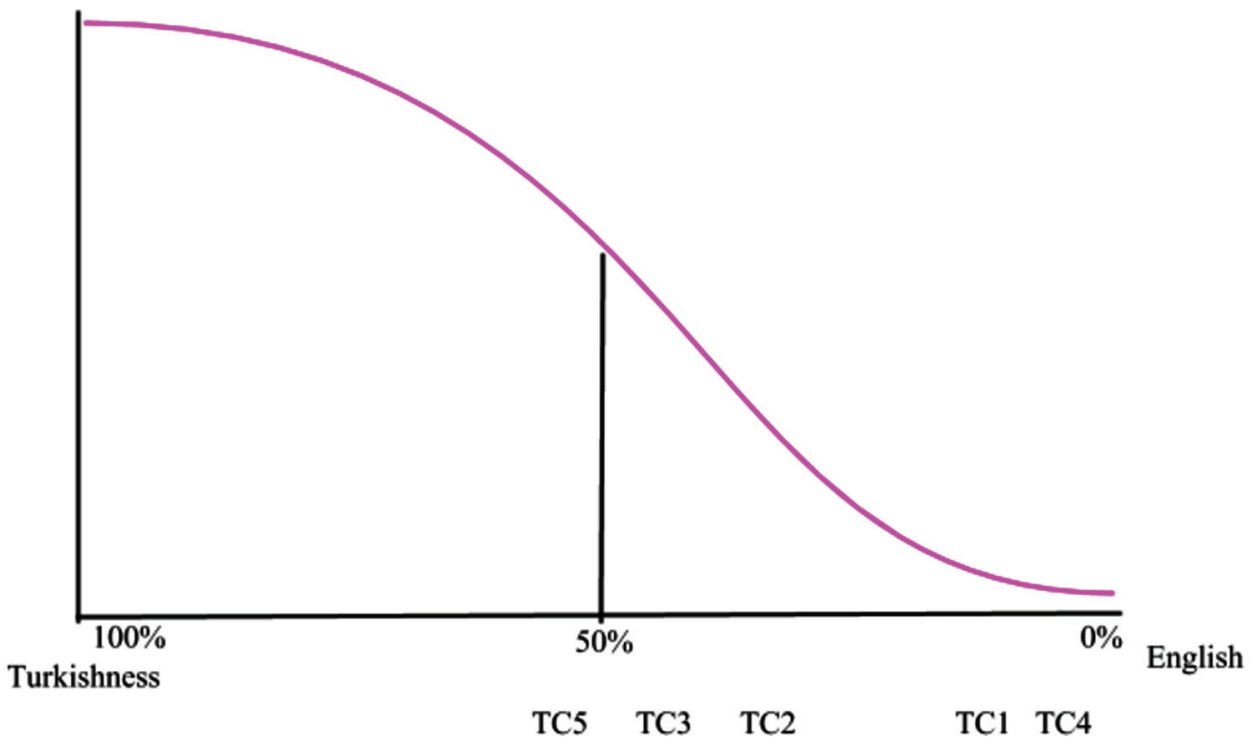


The general tendency among the TCs was to underscore the influence of the British culture. Though the TCs and the TRs share the same language, their historical past (i.e. Cyprus being a postcolonial country) led these two cultures to attach themselves to different identities.

The TCs had ties to the UK, thus access to the monolingual and bilingual English community such as TC expatriates was easier. This in turn affected their lifestyle (e.g. watching English TV channels, using English in their daily life) and hence their identity.

This backs Whorf's (1956 as cited in Woods \& Çakır, 2011) controversial idea that we humans tend to perceive the world (here language classes, students, teaching English) in a way our language predisposes. Accordingly, our languages shape our understandings of our environment, which also clarifies the difference in beliefs among the TCs and those of the TCs and TRs.

Considering TC5's distinction from the rest of the TCs, this could well be described by the identity fluctuations among TCs, resulting from the different socialization of TCs' generations into various socio-political environments (Vural \& Rustemli, 2006).

These fluctuations serve three significant roles in this study. First, it clarifies why some TCs opted for L2 exclusivity (TC1, TC2, and TC4), while others said CS was acceptable (particularly TC3 and TC5). Second, it explains why for TC3 and TC5 the same three words (i.e. 'L1 is alright') can hold different interpretations. It also defines why some participants' leniency towards L1 was challenged by other members in the same group (In the FG, TC3 and TC1 reacted to TC5's claim that 50\% L1 was appropriate) corroborating the discussion that differences also exist within a culture (Littlewood, 2001).

Moving on to the TRs, they were a somewhat 'closed' group whereby their 'Turkishness' was at the center of their identities, implied by their statements regarding L1 and the role of English in their lives. Also, referring to their prior learning experiences and prior teachers it can be inferred that throughout their formal English at schools they had minimum exposure to English and its culture (Atay, 2005 \& Kirkgoz, 2005).

Therefore, referring back to the TC versus TR dichotomy, the distinct perceptions of identity resulting mainly from internal factors and partly from external (TCs not having had the same exposure to Turkish students as the TRs) forged diverse frameworks regarding decisions to code-switch or not. In this respect, based on the participants' descriptions, the TCs were less lenient towards CS (though not TC5) whereas the TRs were more lenient (owing to the diplomatic responses they gave). The TRs did not have boundaries for the use of L1, implying that L2- exclusivity was not at the center of their beliefs:

TR1: [All] English policy is something I never apply. I know people who do it. I also know they are really successful. Really, they ask the kids questions in English, and they never go out of that. I mean like if the students really accept their teachers as (native), the teacher really becomes one. But what I've observed, I mean to be able to do that you have to be (native) or (native like). I mean you have got to be born, brought up abroad or spent some time abroad (....)

Though it is speculative, this also reflects the discussion initiated by Hobbs, Matsuo \& Payne (2010) that unless TR1's cultures of learning are not enhanced by teaching English to native speakers of English, or having to teach in classes with international students, he would still retain his attitude towards L2 exclusivity, even if there were no external factors like exam pressures.

This also accounts for TCs' comments about 50\% and 30\% L1 leniency: 50\% is too much (TC1-FG)... $30 \%$ is ok (TC3-FG). Likewise, it explains why TRs perceived certain aspects (addressing students as friends) as not natural as opposed to what TCs found natural (maximum L2 exposure). Comments like 
'natural' or 'not natural' imply that there are some things with regards to CS that the teachers could not explain (Dilin, Gil-Soon, Kyung-Suk, \& Nan-Ok, 2004). The authors believe cultures of learning account for the variety of these perceptions. Hence, there should be a critical body of research looking at teachers' values and beliefs associated with language, culture and heritage (Lytra, 2011).

\section{Framing Teachers' Expectations of Their Students}

This study also confirmed that teachers' sociocultural background framed teachers' observations and expectations of their students (Wu, 2001). For example, TC teachers' experience of being in the UK or being in close contact with expatriates in learning English, influenced them in expecting their students to use English in class. The reason for this was that this was the code they used when speaking in that language and they all learnt the language by actually speaking it. However, due to the identity fluctuations, the TCs had slightly differing views on this:

There's a student who cannot express himself because his English is not good. But when you let him speak in Turkish, he proves that he is intelligent, and that he can express himself, but not in English (TC2-FG).

But elsewhere he said:

If you want to learn English, learn how to speak it (TC2-INT3).

Considering these quotes, it is deduced that though he empathizes with his students to a certain extent, he also expects them to use L2:

What we did [as students], we tried to speak English. Nobody tried to give an answer to a question in Turkish. We tried to give an English answer because why would you reply in Turkish? It was an English course ... When we didn't know something we would say (oh I don't know) [low pitch voice]. Nobody said 'my hodja I can do it in Turkish' (TC4-FU1).

Moreover, this expectation was so high that the TCs criticized their students for not doing this and at times felt frustrated. For example, in one of his observations TC4 said to his student:

If I speak to you in Greek, speak to me in Greek. If I speak to you in English, speak to me in English (TC4-Obs.3).

This is why TC4 kept reacting to students' L1. He assumed that the students' L1 made him use L1 too, because he was not used to responding in a different code:

... in my family a lot of people speak Greek. But they speak Turkish or they speak Greek. They never mix it up ... Never, not even one word of Turkish or when they are speaking. Because they're [the students] always speaking to me in Turkish I automatically assume oh [I should speak in] Turkish (TC4-POINT1). 
The rest of the TCs also had similar reactions. For example, TC1, TC2 and TC3 complained about the students not using L2 in the POINTS:

I want to be called Miss, that's the way I like it (TC1, POINT2).

Likewise, referring to her past experience in learning vocabulary (e.g. looking up words from a bilingual TC dictionary), TC1 said she wanted her students to learn the synonyms and antonyms of the new words. This backs her policy in teaching vocabulary:

I don't prefer using L1 in teaching vocabulary; I'm totally against it (TC1-FG).

However the following excerpt sees a TC who implies she had enhanced her cultures of learning: she saw the necessity to blend her own expectations with her students'. Thus, she increased her L1 use. In the beginning of the interview, she said $30 \%$ of L1 was appropriate. Her in-class use was also supportive of this. The following excerpt implies that the NCC context was influential in the development of cultures of learning. Not simply because of exam-pressure or heavy schedule but because she came to realize the expectations of her audience, her students, owing to the time she spent here with the TR teachers and students.

When I first came here I didn't find it the same [to my previous teaching experience]. I mean in fact, having to use Turkish was very strange for me. It was very difficult. But then in my second year everything became much easier (...) When you first come you experience a shock! It's a very strange environment for someone coming from there [Britain](...) having to change something you have got used to doing... $(T C 3-F G)$.

The authors believe it equally significant to note here the similarity of her own learning experience as well, whereby she had some room for L1 in learning, particularly English grammar. Thus, her own learning experience also led her to adapt to the context more readily.

Nevertheless, again owing to their socio-cultural background, the TRs were not expectant of their students using L1. Moreover, they either openly said or implied that they wanted their students to make connections in L1 when learning a new structure. This was most probably because they had not been expected to use L1 as students and that by experience they knew that linking with L1 was a good way to learn English. This resemblance of prior learning experience created a tacit agreement between the TR teachers and their TR students.

...I can't be cross with the students. The reason for that is: Why are we speaking in Turkish between us [me and you as the interviewer] because we feel safer and it's not normal. Us speaking in English would be really weird. No matter how much you learn something, if you don't stay for a long time in a country where the language is spoken, what you learn doesn't make you feel enough... But I really understand I mean in class when I do (group work), I don't say speak English...You can discuss ideas using Turkish. I don't say it I mean (encourage) it [English]. I mean let's say I ignore it [Turkish] (TRI-INTI). 
Though it is speculative as to whether L1 was what the students actually expected when learning a new structure (as there were no interviews conducted with the students), there was evidence to suggest so. During the lessons, students kept asking for Turkish explanations. They also tried making L1 connections when learning a new structure or in justifying their answers to the teacher (Though this was discouraged by the TCs: 'You are thinking in Turkish, don't do that!': TC2-Obs. 2).

Teachers have a certain framework, or 'insight' in Ellis's (2006) term, due to their cultures of learning, which guides their teaching (Wu, 2001). The closer the teacher/student culture, the more the teachers are aware of their students' expectations and behave accordingly. The following quotes support this claim:

I give examples from my own learning experience: [how I used to mispronounce city center as] kitty kenter and they feel happy (TR5-FU).

I can empathize with my students because I've studied for the exams, too... I mean sometimes even for me like two weeks before the (midterm) it seems pointless to do (communicative tasks). Because due to my student past, maybe because I was also a part of this system, I know and understand. To ease the process and not to be in (conflict) between them, I try to behave in the way they expect (TR3-FU-1).

There was an 'agenda mismatch' (Nunan, 1995, p.135) between the TR students and particular TC teachers in that the TC teachers were concerned with focusing on the importance of L2-exposure, while the students were busy learning in their own ways (making connections with L1) (Liu \& Littlewood, 1997). This agenda mismatch can also be used to describe the discrepancy among teachers with different cultures of learning.

It has been evidenced above that cultures of learning affect the language used in class. Teachers' distinct frames are reflected in their ideas of leniency, functions, the teachers' role and their perceptions of their learners' receptivity, thereby either reinforcing their commitment to L2 use or contributing to CS (Hobbs, Matsuo \& Payne, 2010).

\section{Framing Teachers' Perceptions of Class Events}

Combining the idea of cultures of learning and teachers' beliefs, this study has shown that teachers' beliefs are culture-or context-laden (Woods \& Çakır, 2011).

Teachers' perceptions of their class events (i.e. the use of L1), compared to their judgments of the success of the lesson (L1 use was or was not appropriate), were dependent on their goals, which were determined by their existing knowledge of how things are and how they are supposed to be. Woods (1997) describes this as 'receptive structuring', where the interpretation of class events does not match the planned structure. TC4, who code-switched only twice in one of his lessons, criticized himself for doing so. Similarly, TC1, TC2, TC3 and TC4 considered their lessons as unsuccessful because their students did not use L2, which was opposed to their own cultures of learning, whereas for the TR teachers, a class of pupils who simply did their work (no matter what language they were using) was deemed successful.

Due to interpretive processes, two teachers' interpretations of what happened in a particular class might differ (Woods, 1997). Teachers have their own personal interpretations of the same idea owing to their individual and, in a broader sense, cultural experiences (Woods \& Çakır 2011). Consequently, a varying perspective towards CS occurred between the TCs and the TRs. 
Language Teachers' Beliefs and Practices

\section{CONCLUSION AND IMPLICATIONS}

\section{Conclusion}

The current study argues that shared groups possess similar knowledge about teaching. Moreover, there are certain factors that make up cultures of learning. These include internal factors and comprise teachers' backgrounds and experiences in teaching. These make up the core cultures of learning in that they act as a frame through which external factors are interpreted. Teachers' sociocultural backgrounds, and their prior learning experiences all add up and form their belief of what works and does not work inclass. That is, they form de facto guidelines.

The extent to which L1 was appropriate changed among TCs and TRs with TCs (though not TC5) having stronger beliefs. Later, it was evidenced that teachers' cultures of learning framed teachers' beliefs: their L1 leniency, their expectations from their students and their overall judgments of their lessons.

This difference among TCs and TRs manifested itself in-class with the different use of functions (in nature) and totals of L1 and L2 usage (in percentages). Here, it was discussed that teachers' beliefs matched their practices and similar to their stated beliefs, teachers' practices were highly influenced by their cultures of learning. Still, the dynamic nature of belief construction was also highlighted with a reference to teachers' (particularly TRs) practices. The findings of this study are partially in line with the findings of similar research (e.g. Woods, 2003; Hobbs, Matsuo \& Payne, 2010).

\section{Possible Implications and Recommendations for Professional Development}

Based on the findings, the authors conclude that teachers enter training courses with existing beliefs (Johnson, 1989; Lortie, 1975). A way to further develop these programs would be to allow those entering to reflect on their personal histories and beliefs and for the course context and training curriculum in turn to mirror these by recognizing potential tensions between them (the beliefs of the teachers in relation to the ontological underpinnings of the course). This will serve to prevent the destabilization of the identities of the teachers and allow teachers to demonstrate the values they aspire to (Flores \& Day, 2006).

Another factor to consider is the causes of the low impact of teacher training courses. The study backs the idea that theoretical (impersonal) knowledge is reshaped (becomes personalized) when theoretical knowledge relates to one's experience due to personalization of ideas (Woods \& Çakır, 2011). Teachers only make sense of new ideas through their own lenses whereby their personal concepts are established through experience and then by rethinking them and expressing themselves verbally. Therefore, it is important that they are given the opportunity to voice their experiences.

Thus, it is significant to consider these influences in designing teacher education programs (Ellis, 2006). For example, it is important to realize the impact previous teachers have on shaping teachers' own knowledge and beliefs by including reflective practices.

The idea that prior learning experience and prior teachers' personal histories contribute to teachers' shaping their belief systems would imply that the construction of beliefs is somewhat personal (Woods, 2003). Moreover, when considered from a cultural perspective, teachers with similar cultural backgrounds exert similar behaviors and have similar expectations of their students (see Hobbs, Matsuo \& Payne, 2010) which may further imply that belief construction relates to a broader, overarching approach; the theory of cultures of learning. 
The authors hope that the findings of this study will serve as lessons to be learnt for language teachers and language teacher educators. It is hoped that future teacher education courses are not designed solely for a general audience but, rather, are also contextualized to fit the cultures of learning of the teachers attending these courses.

\section{REFERENCES}

Aldemir, J., \& Sezer, O. (2009). Early childhood education pre-service teachers' images of teacher and beliefs about teaching. Inonu University Journal of the Faculty of Education, 10(3), 105-122.

Antón, M., \& Dicamilla, F. J. (1999). Socio-Cognitive Functions of L1 Collaborative Interaction in the L2 Classroom. Modern Language Journal, 83(2), 233-247. doi:10.1111/0026-7902.00018

Atay, D. (2005). Reflections on the cultural dimension of language teaching. Language and Intercultural Communication, 5(3-4), 222-236. doi:10.1080/14708470508668897

Auer, P. (1984). Bilingual conversation. Amsterdam: John Benjamins Publishing. doi:10.1075/pb.v.8

Auerbach, E. R. (1993). Re-examining English only in the ESL classroom. TESOL Quarterly, 27(1), 9-32. doi:10.2307/3586949

Borg, S. (2003). Teacher cognition in language teaching: A review of research on what language teachers think, know, believe, and do. Language Teaching, 36(2), 81-109. doi:10.1017/S0261444803001903

Borg, S. (2006). Teacher cognition and language education: Research and practice. London: Bloomsbury Publishing.

Braun, V., \& Clarke, V. (2006). Using thematic analysis in psychology. Qualitative Research in Psychology, 3(2), 77-101. doi:10.1191/1478088706qp063oa

Breen, M. P., Hird, B., Milton, M., Oliver, R., \& Thwaite, A. (2001). Making sense of language teaching: Teachers principles and classroom practices. Applied Linguistics, 22(4), 470-501. doi:10.1093/ applin/22.4.470

Canagarajah, A. S. (1995). Functions of codeswitching in ESL classrooms: Socializing bilingualism in Jaffna. Journal of Multilingual and Multicultural Development, 16(3), 173-195. doi:10.1080/0143463 2.1995.9994599

Chambers, P. (1991). Promoting use of the target language in the classroom. Language Learning Journal, 4(1), 27-31. doi:10.1080/09571739185200411

Charmaz, K. (2006). Constructing grounded theory: A practical guide through qualitative analysis. London: Sage Publications.

Cummins, J. (2000). Language, Power and Pedagogy. Clevedon, UK: Multilingual Matters.

De La Campa, J. C., \& Nassaji, H. (2009). The amount, purpose, and reasons for using L1 in L2 classrooms. Foreign Language Annals, 42(4), 742-759. doi:10.1111/j.1944-9720.2009.01052.x 
Dilin, L., Gil-Soon, A., Kyung-Suk, B., \& Nan-Ok, H. (2004). South Korean high school English teachers code switching: Questions and challenges in the drive for maximal use of English in teaching. TESOL Quarterly, 38(4), 605-638. doi:10.2307/3588282

Ellis, E. M. (2006). Language learning experience as a contributor to ESOL teacher cognition. TESL-EJ, 10(1), 1-20. Available from: http://tesl-ej.org/pdf/ej37/a3.pdf

Evans, M. (2009). Using stimulated recall to investigate pupils thinking about online bilingual communication: Code-switching and pronominal address in L2 French. British Educational Research Journal, 35(3), 469-485. doi:10.1080/01411920903017986

Flores, M. A., \& Day, C. (2006). Contexts which shape and reshape new teachers identities: A multiperspective study. Teaching and Teacher Education, 22(2), 219-232. doi:10.1016/j.tate.2005.09.002

Hobbs, V., Matsuo, A., \& Payne, M. (2010). Code-switching in Japanese language classrooms: An exploratory investigation of native vs. non-native speaker teacher practice. Linguistics and Education, 21(1), 44-59. doi:10.1016/j.linged.2009.12.004

Jin, L., \& Cortazzi, M. (2006). Changing practices in Chinese cultures of learning. Language, Culture and Curriculum, 19(1), 5-20. doi:10.1080/07908310608668751

Johnson, K. E. (1994). The emerging beliefs and instructional practices of preservice English as a second language teachers. Teaching and Teacher Education, 10(4), 439-452. doi:10.1016/0742-051X(94)90024-8

Johnson, M. (1989). Embodied knowledge. Curriculum Inquiry, 19(4), 361-377. doi:10.1080/036267 84.1989.11075338

Kirkgoz, Y. (2005). English language teaching in Turkey: Challenges for the $21^{\text {st }}$ century. In G. Braine (Ed.), Teaching English to the world: History, curriculum, and practice (pp. 159-171). Mahwah, NJ: Lawrence Erlbaum Associates, Inc.

Kraemer, A. (2006). Teachers use of English in communicative German language classrooms: A qualitative analysis. Foreign Language Annals, 39(3), 435-450. doi:10.1111/j.1944-9720.2006.tb02898.x

Krashen, S. (1982). Principles and practice in second language acquisition. New York, NY: Pergamon.

Levis, J., \& Farrell, T. S. (2007). Failing the practicum: Narrowing the gap between expectations and reality with reflective practice. TESOL Quarterly, 41(1), 193-201. doi:10.1002/j.1545-7249.2007.tb00049.x

Lin, A. M. Y. (2013). Classroom code-switching: Three decades of research. Applied Linguistics Review, 4(1), 195-218. doi:10.1515/applirev-2013-0009

Littlewood, W. (2001). Students' attitudes to classroom English learning: A cross-cultural study. Language Teaching Research, 5(1), 3-28.

Liu, N. F., \& Littlewood, W. (1997). Why do many students appear reluctant to participate in classroom learning discourse? System, 25(3), 371-384. doi:10.1016/S0346-251X(97)00029-8

Lortie, D. (1975). Schoolteacher: A sociological study. Chicago: University of Chicago Press. 
Lytra, V. (2011). Negotiating language, culture and pupil agency in complementary school classrooms. Linguistics and Education, 22(1), 23-36. doi:10.1016/j.linged.2010.11.007

Moore, A., Edwards, G., Halpin, D., \& George, R. (2002). Compliance, resistance and pragmatism: The (re)construction of schoolteacher identities in a period of intensive educational reform. British Educational Research Journal, 28(4), 551-565. doi:10.1080/0141192022000005823

Numrich, C. (1996). On becoming a language teacher: Insights from diary studies. TESOL Quarterly, 30(1), 131-153. doi: $10.2307 / 3587610$

Nunan, D. (1995). Closing the gap between learning and instruction. TESOL Quarterly, 29(1), 133-158. doi: $10.2307 / 3587808$

Pajares, M. F. (1992). Teachers beliefs and educational research: Cleaning up a messy construct. Review of Educational Research, 62(3), 307-332. doi:10.3102/00346543062003307

Pan, Y. C., \& Pan, Y. C. (2010). The use of L1 in the foreign language classroom. Colombian Applied Linguistics Journal, 12(2), 87-96.

Payne, M. (2011). Exploring Stephen Krashens i+ 1 acquisition model in the classroom. Linguistics and Education, 22(4), 419-429. doi:10.1016/j.linged.2011.07.002

Polio, C. G., \& Duff, P. A. (1994). Teachers language use in university foreign language classrooms: A qualitative analysis of English and target language alternation. Modern Language Journal, 78(3), 313-326. doi:10.1111/j.1540-4781.1994.tb02045.x

Selvi, A. F. (2014). The medium-of-instruction debate in Turkey: Oscillating between national ideas and bilingual ideals. Current Issues in Language Planning, 15(2), 133-152. doi:10.1080/14664208.20 14.898357

Seng, G. H., \& Hashim, F. (2006). Use of L1 in L2 reading comprehension among tertiary ESL learners. Reading in a Foreign Language, 18(1).

Tabaku, E. (2014). Code-switching: Beliefs and attitudes of Albanian pre-service English teachers. Journal of Educational and Social Research, 4(2), 384-389.

Toribio, A. J. (2001). On the emergence of bilingual code-switching competence. Bilingualism: Language and Cognition, 4(3), 203-231. doi:10.1017/S1366728901000414

Vural, Y., \& Rustemli, A. (2006). Identity fluctuations in the Turkish Cypriot community. Mediterranean Politics, 11(3), 329-348. doi:10.1080/13629390600913916

Wellington, J. (2000). Educational research: Contemporary issues and practical approaches. London: Continuum.

Willans, F. (2011). Classroom code-switching in a Vanuatu secondary school: Conflict between policy and practice. International Journal of Bilingual Education and Bilingualism, 14(1), 23-38. doi:10.1080/13670050903576038 
Woods, D. (1996). Teacher cognition in language teaching: Beliefs, decision-making and classroom practice. Cambridge, UK: Cambridge University Press.

Woods, D. (1997). Decision-making in language learning: A lens for examining learner strategies. Language Teaching, 20(10). Retrieved from http://jalt-publications.org/old_tlt/files/97/oct/woods.html

Woods, D. (2003). The social construction of beliefs in the language classroom. In P. Kalaja \& A. M. F. Barcelos (Eds.), Beliefs about SLA: New research approaches (pp. 201-229). New York, NY: Springer. doi:10.1007/978-1-4020-4751-0_9

Woods, D., \& Çakır, H. (2011). Two dimensions of teacher knowledge: The case of Communicative language teaching. System, 39(3), 381-390. doi:10.1016/j.system.2011.07.010

Wu, Y. (2001). English language teaching in China: Trends and challenges. TESOL Quarterly, 35(1), 191-194. doi:10.2307/3587867

Yavuz, F. (2012). The attitudes of English teachers about the use of L1 in the teaching of L2. Procedia: Social and Behavioral Sciences, 46, 4339-4344. doi:10.1016/j.sbspro.2012.06.251

Yuan, Y. (2001). An inquiry into empirical pragmatics data-gathering methods: Written DCTs, Oral DCTs, field notes, and natural conversations. Journal of Pragmatics, 33(2), 271-292. doi:10.1016/ S0378-2166(00)00031-X

\section{ENDNOTES}

Certificate for Overseas Teachers of English.

Diploma in Overseas Teaching of English.

English Language and Humanities.

Certificate in Teaching English to Speakers of Other Languages.

American Culture and Literature.

Master of Education.

Certificate in English Language Teaching to Adults.

In-service Certificate in Language teaching.

English Language and Teaching.

10 English Language and Literature. 